\title{
The Discipline and Professional Development Mode of Chinese Undergraduate Universities
}

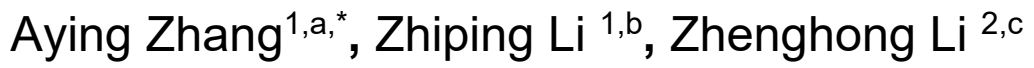 \\ ${ }^{1}$ Harbin University, 150086 Harbin, China \\ ${ }^{2}$ Harbin Institute of Technology, 150001 Harbin, China \\ a,*zaying@sina.com, blizp2008@126.com, c273662999@qq.com
}

Keywords: Professional development, mode, Undergraduate, Universities.

\begin{abstract}
Specialty is the basic unit of personnel training based on disciplines and according to the needs of social and vocational division of labor. Discipline is a relatively independent system of knowledge in which human beings divide their own knowledge into groups according to the object of cognition in their cognitive and research activities. The discipline and specialty are interrelated. The specialty is based on discipline, discipline is the foundation of specialty, discipline is the raw material of specialty, and specialty is the choice and organization of discipline. The discipline construction is a developmental intervention by undergraduate universities to the basic units of personnel training and scientific research. The professional development is the developmental intervention of undergraduate universities to the basic units of personnel training.
\end{abstract}

\section{Connotation of discipline and professional in undergraduate university}

\subsection{Connotation of discipline}

Discipline is a relatively independent system of knowledge in which human beings divide their own knowledge into groups according to the object of cognition in their cognitive and research activities.

The research shows that the disciplines are the classification of academics (a scientific field or a branch of science) and the subjects of teaching (the basic unit of school teaching content). Disciplines are the classification of academics (a certain scientific field or a branch of science) and the subjects of teaching (a system of knowledge and skills organized according to certain teaching theories, the basic unit of school teaching content).

We believe that the first is the classification of systematic knowledge, the second is the basic organizational unit of academia, and the third is the subject of school teaching.

\subsection{Connotation of professional}

Specialty is the basic unit of personnel training based on disciplines and according to the needs of social and vocational division of labor.

Specialty has three levels: broad sense, narrow sense and special reference. Broad sense of specialty refers to some specific labor characteristics different from other occupations. Narrow sense of specialty mainly refers to certain specific social occupations (the employees of these occupations are engaged in more advanced, complex and highly specialized mental work). It's refers to the profession that is the major in higher education.

Specialty is the academic category which is divided by higher education or secondary professional school according to the division of labor needs of society. Specialty is a special field for higher education to train students according to the division of social occupation, the classification of subjects, the development of science, technology and culture, and the needs of economic construction and social development.

In our opinion, as far as social division of labor is concerned, specialty refers not only to the specialization of profession or profession, but also to the specialization of mental work of employees; 
as far as schools are concerned, specialty refers to the classification of subjects and social division of labor and the classification of studies.

\subsection{Relationship between discipline and profession}

According to the constitution of subject and specialty, subject is composed of the object of subject research, the law of subject object (theoretical system) and the method of scientific research. Specialty is composed of the goal of specialty training, the plan of specialty training (curriculum system), the teachers and students of specialty and the teaching conditions of specialty.

According to the principle of dividing disciplines and setting up majors, the division of disciplines follows the logic of the knowledge system itself. Majors are set up according to the classification of disciplines and the needs of the society for specialists in different fields and posts.

Generally speaking, discipline and specialty are interrelated. On the one hand, a major is composed of a number of disciplines, specifically, by a number of disciplines suitable for a professional needs of the content of some disciplines, that is, the professional knowledge of the division and organization of disciplines, that is, the professional knowledge of various disciplines in accordance with the requirements of social occupation for the knowledge of talent and organization.

On the other hand, a subject category corresponds to a number of industries and is thus divided into several specialties, sometimes a subject is a specialty. Therefore, specialty is based on discipline, discipline is the foundation of specialty, discipline is the raw material of specialty, and specialty is the choice and organization of discipline.

\section{Basic mechanism of teaching staff construction in Undergraduate Universities}

\subsection{Contents of discipline construction in Undergraduate Universities}

The discipline construction is a developmental intervention by undergraduate universities to the basic units of personnel training and scientific research. Generally speaking, the main elements of discipline construction are subject leaders, discipline echelon, scientific research topics, research instruments and equipment, discipline construction management personnel, which mainly includes three aspects: discipline direction construction, discipline echelon construction, discipline base construction (scientific research project construction).

\subsection{Contents of profession construction in Undergraduate Universities}

The professional development is the developmental intervention of undergraduate universities to the basic units of personnel training.

Generally speaking, the major elements of specialty construction are teachers, courses, teaching materials, experiments, teaching managers, etc. The main contents are specialty settings and curriculum structure, curriculum and textbook construction, specialty faculty construction, specialty conditions (laboratory, practice base, books and materials, etc.) construction, specialty construction policies, etc.

\section{Development patterns of disciplines and specialties in Undergraduate Universities}

\subsection{Professional development mode of Undergraduate Universities}

\subsubsection{Adjusting professional structure and adapting to social needs}

The way for undergraduate universities to meet the needs of social economy for senior specialists is to set up majors for personnel training. The demand of social economy for high-level specialists is varied, and the specialties offered by undergraduate universities should also be varied.

The undergraduate universities set up majors, adjust majors and determine the training objectives according to the social and economic needs. Thus, the undergraduate universities have established a relatively stable and reasonable professional system oriented by social needs. This professional system is the starting point of professional development. 


\subsubsection{Optimizing curriculum structure and meeting training requirements}

The demand of social and economic needs for high-level professionals, on the one hand, requires that they have systematic professional knowledge, on the other hand, requires that they have a strong practical ability, the era of knowledge-based economy also requires that they have a certain spirit of innovation and entrepreneurial ability.

The specialties offered by undergraduate universities should fully understand the social needs and carefully design the curriculum structure so as to provide a professional knowledge structure for training senior specialists and lay a foundation for serving the society. This course structure is the core of professional development.

\subsubsection{Strengthening teachers' construction and improving teaching quality}

With the professional settings to meet the needs of the society and the curriculum system to meet the needs of training senior specialized personnel, undergraduate universities should also have a contingent of teachers to meet the requirements of teaching quality.

Teachers' team building should be based on the professional and curriculum requirements, on the one hand, through training and other means to promote teachers to improve the quality of education and teaching, on the other hand, to take effective measures to introduce the badly needed talents, improve the structure of the teaching team, and build a teaching team to meet the requirements of Education and teaching. This faculty is the key to professional development.

\subsubsection{Increase capital investment and consolidate professional conditions}

Undergraduate universities should strengthen the construction of professional conditions, including laboratory construction, practice base construction, books and materials procurement and other professional conditions.

Complete laboratories and practice bases have laid a foundation for improving students' innovative spirit and practical ability. High-quality textbooks and books provide students with solid basic knowledge and rich professional knowledge. This professional condition is the supporting point of professional construction.

\subsubsection{Establishing effective mechanism and promoting professional development}

Under the framework of the presidential responsibility system under the leadership of the Party committee, undergraduate universities should make overall plans for the relationship between administrative power and academic power, give full play to the role of teachers, especially professors, respect knowledge and talents, improve the status and role of academic work, and establish a good atmosphere and effective mechanism for academic freedom for professional development. Ensure system guarantee. This management system is the driving force of professional development.

\subsection{Discipline development mode in Undergraduate Universities}

\subsubsection{Making policies and promoting discipline construction}

Discipline is the leader of undergraduate universities, and the carrier of producing symbolic academic achievements, improving the level of running a school, improving the social reputation and influence of undergraduate universities.

Undergraduate universities should start from the high vision of University development, attach importance to academia and advocate academics, formulate sound discipline development policies within the framework of school development, specify the direction of discipline construction, standardize discipline construction behavior, and promote discipline construction and development. This is a strategic measure for the discipline development of undergraduate universities as well as an undergraduate university. A long-term plan for discipline development. Discipline policy formulation is the direction of discipline construction in undergraduate universities.

\subsubsection{High-end leading, concise research direction}

The undergraduate universities, facing the frontier of scientific research and the demand of social economy for high and new technology, should condense the direction of discipline research at the high-end level of science and technology; the undergraduate universities should condense the research direction with original innovation in the basic research field and the research direction with practical value in the applied research field. 
Undergraduate universities also have to face the actual problems in the social and economic development, concise research direction with research advantages. The determination of research direction is the key point of discipline construction in undergraduate universities.

\subsubsection{Optimizing structure and gathering discipline team}

Disciplines need to establish a reasonable contingent of disciplines, of which the subject leader is the most important, because disciplines and subject leaders often walk together. The undergraduate universities form a team of discipline leaders by vigorously cultivating and introducing master-level academic personnel, and the undergraduate universities form a backbone team of disciplines by focusing on training and introducing outstanding academic personnel.

Discipline leaders and backbones should not only have a high level of academic accomplishment, but also have a good coordinating and organizing ability and personality charm, especially the introduction of high-level and high-level discipline leaders and backbones, and even have the spirit of sacrifice, which should be integrated into the discipline team as soon as possible, and organize everyone to jointly undertake projects and joint scientific research. Research and publish results together to create a new prospect for academic research.

It is worth mentioning that undergraduate universities should form a flourishing academic career, a relaxed and elegant academic environment, a fair and reasonable salary system, stabilize the discipline team, optimize the discipline structure, give full play to the discipline function, and promote the development of the discipline. The convergence of discipline teams is the core of discipline construction in undergraduate universities.

\subsubsection{Integrating resources and building discipline base}

Discipline base construction of undergraduate universities includes subject research projects, subject research achievements and subject research base construction. Subject research project is a national, provincial and municipal scientific research project undertaken by the discipline team in the direction of discipline. The level of project increases with the development of discipline construction.

Achievements of subject research are obtained by the team of subjects in the course of the research of subject projects, and the level of achievements increases with the deepening of scientific research. The construction of subject research base mainly refers to the construction of key laboratories, specialized laboratories, engineering centers, research bases, experimental bases and industrialization bases. First, plan, collect funds, gather talents and share resources. The construction of discipline base is the supporting point for the construction of major disciplines.

\section{Acknowledgement}

This research was financially supported by Heilongjiang Social Science Foundation (Grant No. 17SHD204).

\section{References}

[1] Z. P. Li, W. D. Wu: China Higher Education Research vol. 6 (2005), pp. 39

[2] Z. P. Li: Heilongjiang Researches on Higher Education vol. 3 (2005), pp. 22

[3] Z. P. Li: Education Exploration vol. 4 (2005), pp. 38

[4] Z. P. Li and et al: Journal of Harbin University vol. 10 (2005), pp. 64

[5] Z. P. Li, W. D. Wu: China Higher Education Research vol. 7 (2006), pp. 56 